\title{
Romidepsin (FK228) regulates the expression of the immune checkpoint ligand PD-L1 and suppresses cellular immune functions in colon cancer
}

\author{
Yehui Shi ${ }^{1,2,4} \cdot$ Ying $\mathrm{Fu}^{3,4,5} \cdot$ Xin Zhang ${ }^{3,4,5}$. Gang Zhao ${ }^{3,4,5} \cdot$ Yuan Yao ${ }^{3,4,5} \cdot$ Yan Guo ${ }^{4,6}$. Gang Ma ${ }^{3,4,5}$. Shuai Bai ${ }^{3,4,5}$. \\ Hui $\mathrm{Li}^{3,4,5}$
}

Received: 9 December 2019 / Accepted: 25 June 2020 / Published online: 6 July 2020

(c) The Author(s) 2020

\begin{abstract}
Romidepsin (FK228), a histone deacetylase inhibitor (HDACi), has anti-tumor effects against several types of solid tumors. Studies have suggested that HDACi could upregulate PD-L1 expression in tumor cells and change the state of anti-tumor immune responses in vivo. However, the influence of enhanced PD-L1 expression in tumor cells induced by romidepsin on anti-tumor immune responses is still under debate. So, the purpose of this study was to explore the anti-tumor effects and influence on immune responses of romidepsin in colon cancer. The results indicated that romidepsin inhibited proliferation, induced G0/G1 cell cycle arrest and increased apoptosis in CT26 and MC38 cells. Romidepsin treatment increased PD-L1 expression in vivo and in vitro via increasing the acetylation levels of histones $\mathrm{H} 3$ and $\mathrm{H} 4$ and regulating the transcription factor BRD4. In subcutaneous transplant tumor mice and colitis-associated cancer (CAC) mice, romidepsin increased the percentage of FOXP 3 regulatory T cells (Tregs), decreased the ratio of Th1/Th2 cells and the percentage of IFN- $\gamma+$ CD8+ $\mathrm{T}$ cells in the peripheral blood and the tumor microenvironment. Upon combination with an anti-PD-1 antibody, the antitumor effects of romidepsin were enhanced and the influence on CD4+ and CD8+ T cells was partially reversed. Therefore, the combination of romidepsin and anti-PD-1 immunotherapy provides a more potential treatment for colon cancer.
\end{abstract}

Keyword Histone deacetylase inhibitor (HDACi) · Romidepsin · PD-L1 · BRD4 · Regulatory T cells · Colon cancer

Yehui Shi, Ying Fu and Xin Zhang contributed equally to this work.

\footnotetext{
Hui Li

lihui@tjmuch.com

Yehui Shi

shiyehui@tjmuch.com

Ying $\mathrm{Fu}$

fuying9088@163.com

Xin Zhang

zxx_124611966@qq.com

Gang Zhao

gang_zhao1986@126.com

Yuan Yao

bioyuan1927@163.com

Yan Guo

guoyan@tjmuch.com

Gang Ma

horsegang@163.com

Shuai Bai

baishuai6@163.com
}

1 Medical Oncology Department of Breast Cancer, Tianjin Medical University Cancer Institute and Hospital, Huanhuxi Road, Hexi District, Tianjin 300060, People's Republic of China

2 Phase I Clinical Trial Ward, Tianjin Medical University Cancer Institute and Hospital, Tianjin 300060, People's Republic of China

3 Department of Gastrointestinal Cancer Biology, Tianjin Medical University Cancer Institute and Hospital, Tianjin 300060, People's Republic of China

4 National Clinical Research Center for Cancer, Tianjin 300060, People's Republic of China

5 Key Laboratory of Cancer Immunology and Biotherapy, Tianjin, China, Tianjin 300060, People's Republic of China

6 Department of Cancer Biobank, Tianjin Medical University Cancer Institute and Hospital, Tianjin 300060, People's Republic of China 


$\begin{array}{ll}\text { Abbreviations } \\ \text { AOM } & \text { Azoxymethane } \\ \text { BRD4 } & \text { Bromodomain-containing protein } 4 \\ \text { CAC } & \text { Colitis-associated cancer } \\ \text { DSS } & \text { Dextran sodium sulfate } \\ \text { HDACi } & \text { Histone deacetylase inhibitor } \\ \text { HDACs } & \text { Histone deacetylases } \\ \text { MFI } & \text { Mean fluorescence intensity } \\ \text { PD-1 } & \text { Programmed cell death 1 } \\ \text { PD-L1 } & \text { Programmed cell death-Ligand 1 } \\ \text { TCR } & \text { T cell receptor } \\ \text { Tregs } & \text { Regulatory T cells }\end{array}$

\section{Introduction}

Histone deacetylases (HDACs) are important mediators of epigenetic regulation by removing acetyl groups from lysine residues of histones and some nonhistone proteins. Deacetylation of histones can affect chromatin conformation and inhibit gene expression, and the stability and biological functions of some transcription factors are also influenced by their acetylation state. HDACs are phylogenetically classified as class I (HDACs 1, 2,3 and 8), class II (HDACs 4-7, 9 and 10), class III (SIRTs 1-7)s and class IV (HDAC 11). Dysfunction of HDACs has been confirmed to be closely related to the occurrence and development of tumors [1].

HDAC inhibitors (HDACis) can inhibit HDAC-mediated deacetylation, causing the hyperacetylation of histones and the re-expression of epigenetic silencing genes [2]. Importantly, HDACis exert anti-tumor effects through varieties of pathways, including inducing cell cycle arrest (p21, cyclins) and cell apoptosis, regulating cell autophagy, inhibiting tumor angiogenesis (HIF-1a, VEGF), as well as regulating immune response (antigen presentation, $\mathrm{T}$ cell activation and Tregs differentiation) [3-8]. The first HDAC inhibitor vorinostat (also known as Zolinza or SAHA) was approved by US FDA for the treatment of cutaneous T cell lymphoma in 2006. Thereafter, romidepsin (FK228), belinostat (PXD101) and panobinostat (LBH589) were successively approved by FDA for the treatment of cutaneous $\mathrm{T}$ cell lymphoma (CTCL), peripheral T-cell lymphoma (PTCL) and multiple myeloma (MM). HDACis have become a hot spot in antitumor drug research.

Romidepsin, a naturally occurring selective inhibitor of HDACs 1 and 2, has been reported to induce cell cycle arrest and apoptosis in various solid tumor cells, including ovarian cancer and hepatocellular carcinoma $[9,10]$. In addition to direct cytotoxicity, romidepsin can cause a wide range of immune changes like other HDAC inhibitors through the expression of costimulatory molecules (PD-L1), MHC, tumor antigens and cytokines [11-14]. It has been reported that HDACi increased the expression of FOXP3 and the suppressive activity of regulatory $\mathrm{T}$ cells in inflammation and transplantation models [15-17].

Therefore, we analyzed the efficacy of romidepsin in upregulating PD-L1 in murine colon cancer cells and its influence on T cell functions in this study. Although the role of PD-L1 upregulation in immune response against tumor has been controversial, the results herein demonstrated that the combination of romidepsin and anti-PD-1 treatment could effectively inhibit tumor growth in vivo. These data provide a potential option for combinatorial therapy for treating colon cancer.

\section{Materials and methods}

\section{Cell lines and reagents}

The mouse colon cancer cell lines CT26 and MC38 were obtained from the ATCC (Manassas, VA, USA) and cultured in RPMI-1640 with $10 \%$ FBS. All cells were maintained under humidified condition $\left(37^{\circ} \mathrm{C}, 5 \% \mathrm{CO}_{2}\right)$, and continual culture did not exceed 2 months. Romidepsin was purchased from Selleck Chemicals (Houston, TX, USA). An anti-PD-1 antibody was purchased from Biolegend (San Diego, CA, USA). Nontarget and BRD4-targeting siRNAs were purchased from RiboBio Co., Ltd. (Guangdong, China).

\section{Antibodies}

The following antibodies (Abs) were used for Western blotting: rabbit anti-pan-Akt mAb (\#4691), anti-p-Akt (T308) mAb (\#4056), anti-p-Akt (S473) mAb (\#4060), anti-panERK mAb (\#4695), anti-p-ERK (T202/Y204) mAb (\#4376), anti-BRD4 (\#13,440), anti-H3(\#4499), anti-H4(\#13,919), anti-acetyl-H3(Lys9/Lys14) (\#9677), anti-acetyl-H3 (Lys27) (\#8173), anti-acetyl-H4 (Lys5) (\#8647), anti-acetyl-H4 (Lys8) (\#2594), anti-acetyl-H4 (Lys16) (\#13,534) and antiacetylated-lysine (\#9441); all of these were purchased from Cell Signaling Technology (Danvers, MA, USA). Mouse anti-GAPDH mAb (G8795) was purchased from SigmaAldrich. Goat anti-PD-L1 (AF1019) was purchased from R\&D Systems (Minneapolis, MN, USA).

\section{Apoptosis and proliferation analysis using flow cytometry}

Apoptosis and proliferation in CT26 and MC38 cells were analyzed using an Annexin V-FITC Apoptosis Detection Kit II (BD) and BrdU Cell Proliferation Assay Kit (BD), respectively. The results were measured using a FACS Canto II (BD). Representative results of independent assays are shown. 


\section{RNA interference}

For the transient knockdown of BRD4 expression, CT26 and MC38 cells were seeded in 6-well plates and transfected with nontarget or BRD4-targeting siRNA pool using HiPerFect (Qiagen, German) according to the manufacturer's instructions. The working concentration of siRNAs was $100 \mathrm{nM}$.

\section{RNA and RT-qPCR}

RNA was extracted using TRIzol (Thermo Fisher Scientific), and cDNA was synthesized using a PrimeScript ${ }^{\mathrm{TM}}$ RT Reagent Kit (TaKaRa). The qPCR assays were performed using SYBR ${ }^{\circledR}$ Premix Ex Taq ${ }^{\mathrm{TM}}$ II (TaKaRa) and a QuantStudio $^{\text {TM }} 5$ Real-Time PCR System (Thermo Fisher Scientific). GAPDH was used simultaneously as the internal control. One representative result of three independent assays is shown.

\section{Western blotting}

Cell lysis buffer (100 mM NaCl, $10 \mathrm{mM}$ EDTA (pH 8.0), $50 \mathrm{mM}$ Tris- $\mathrm{Cl}(\mathrm{pH} 8.0)$ and $0.5 \%$ (v/v) Triton X-100) with EDTA-free complete protease and phosphatase inhibitors (Roche) was used for protein extraction. The lysates were separated on a 10\% SDS-PAGE gel and transferred onto PVDF membranes. The targets were detected using an Amersham Imager 600 (GE). GAPDH was used as the loading control.

\section{Immunoprecipitation}

The CT26 and MC38 cells were treated with romidepsin for 24 h. Then, a Universal Magnetic Co-IP Kit (Active Motif) was used to harvest the acetylated proteins. Western blotting was used to detect the levels of histone 3 and histone 4 in the acetylated proteins.

\section{Subcutaneous transplantation tumor models}

This study was carried out in accordance with laboratory animal-guideline for Ethical review of animal Welfare and approved by Institutional Animal Care and Use Committee of Tianjin Medical University Cancer Institute \& Hospital (approval No. 2014035). Six-week-old female BALB/C mice (Beijing Vital River Laboratory Animal Technology Co., Ltd) were acclimatized in the Laboratory Animal Resource Center at Tianjin Tumor Hospital. CT26 cells $\left(1 \times 10^{6}\right)$ diluted in PBS were implanted subcutaneously (s.c.) in the flank regions of the mice. When the tumors became palpable, 32 mice were randomized into four experimental groups. Based on previous studies, the mice were given intraperitoneal (i.p.) injections of $300 \mu \mathrm{g}$ per mouse anti-PD-1 (diluted in sterile PBS) on days $14,16,18,20,22,24,26,28,30$ post-tumor implantation and romidepsin $(1 \mathrm{mg} / \mathrm{kg}$ dissolved in DMSO and diluted in sterile PBS) on days $15,17,19,21,23,25,27,29$. This schedule was repeated for a total of 30 days. The mice in the control group were treated with PBS. The mice were killed when the tumors reached a length $\geq 2 \mathrm{~cm}$. Tumor volumes $\left(\mathrm{mm}^{3}\right)$ were calculated with the following formula: tumor volume $=1 / 2$ (length $\times$ width $^{2}$ ), where the width and the length were the shortest and the longest diameters, respectively, as measured by calipers every 2 days. At the end of the study, the mice were killed. The tumors were weighed and prepared as lysates.

\section{Colitis-associated cancer (CAC) models}

CAC was induced with azoxymethane (AOM)/dextran sodium sulfate (DSS) as follows: Briefly, C57BL/6 mice were injected intraperitoneally with $12.5 \mu \mathrm{g} / \mathrm{g}$ AOM (Sigma, St. Louis, MO, USA) on the first day. After 5 days, the mice were given drinking water containing 3\% DSS for 5 days. On day 70, 28 mice were randomized into four experimental groups $(n=7)$. Based on previous studies, the mice received i.p. injections of $300 \mu \mathrm{g}$ per mouse anti-PD-1 (diluted in sterile PBS) on days 72,74 and 76 and romidepsin $(1 \mathrm{mg} / \mathrm{kg}$ dissolved in DMSO and diluted in sterile PBS) on days 71, 73 and 75. The colons were collected, and the tumors were counted and measured.

\section{Flow cytometry analysis}

The following mouse Abs were used for flow cytometry analyses: anti-CD25 $(101,908)$, anti-CD8 $(100,706)$, anti-IFN- $\gamma$ $(113,604)$ and anti-PD-L1 $(124,311)$; these antibodies were all purchased from Biolegend. Anti-CD4 (\# 45-0042-82), anti-FOXP3 (\#17-5773-82) and anti-IL-4 (\# 25-7041-82) were purchased from Thermo Fisher. Gates were determined using isotype control Ab staining. Data were acquired with a FACS Canto II (BD) and expressed as the mean of five separate experiments.

\section{Statistical analysis}

The data were analyzed by two-tailed Student's $t$ test or ANOVA using GraphPad Prism software (La Jolla, CA). Comparisons between groups are presented as the mean \pm SEM. Values of $p<0.05$ were considered statistically significant.

\section{Results}

\section{Romidepsin showed anti-tumor activity against murine colon cancer}

The effects of romidepsin on the proliferation, cell cycle and apoptosis of the murine colon cancer cell lines were 
evaluated. CT26 and MC38 cells were treated with or without romidepsin for $24 \mathrm{~h}$, then measured by Brdu cell cycle assay. We observed a dramatic decrease in the number of cells in the $\mathrm{S}+\mathrm{G} 2 / \mathrm{M}$ phase and a significant increase in the number of cells in the G0/G1 phase after romidepsin treatment (Fig. 1a). And the expression level of PCNA was also downregulated, which suggested the proliferation inhibition effects of romidepsin (Fig. 1b). Compared to the control cells, romidepsin-treated cells had a marginal increase in apoptotic events (Fig. 1c), which was validated by the increased caspase 3 cleavage (Fig. 1d). We further examined the responses of romidepsin in vivo using subcutaneous tumor-transplanted mice and CAC mice. Subcutaneous transplantation tumor mouse models were established by inoculating CT26 cells. After 16 days of treatment with romidepsin, tumor size and weight were obviously reduced compared with the control group (Fig. 2a). The expression of cleaved-caspase 3 in romidepsin-treated group was also upregulated (Fig. 2b).In the CAC model, colon cancer was induced by AOM and 3\% DSS treatment for 70 days and then treated with romidepsin three times (Fig. 2c). The average number of tumors per mouse was used as criterion of efficacy, which was divided based on size $(<5 \mathrm{~mm}$ and $\geq 5 \mathrm{~mm}$ in the largest dimension). The average number of tumors $\geq 5 \mathrm{~mm}$ per mouse was lower in the romidepsin treatment group than in the control group, while there was no obvious difference in the number of tumors with sizes $<5 \mathrm{~mm}$ between the two groups (Fig. $2 \mathrm{~d}$ ). These results showed that romidepsin could inhibit colon cancer growth in vitro and in vivo by inhibiting cancer cell proliferation, inducing cell cycle arrest and promoting apoptosis.

\section{Romidepsin upregulated PD-L1 in mouse colon cancer cells}

Our study indicated that romidepsin arrested colon cancer growth directly. We further analyzed its effects on PD-L1 expression in cancer cells and immune responses.

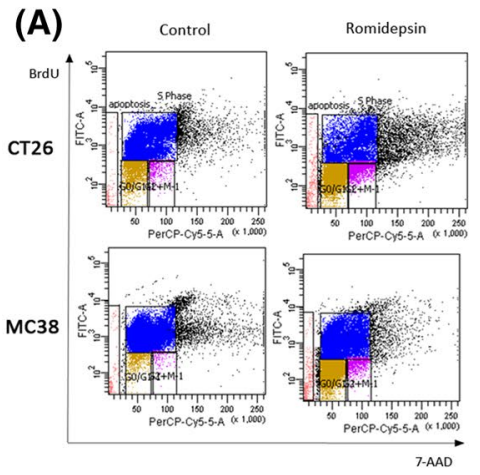

(C)
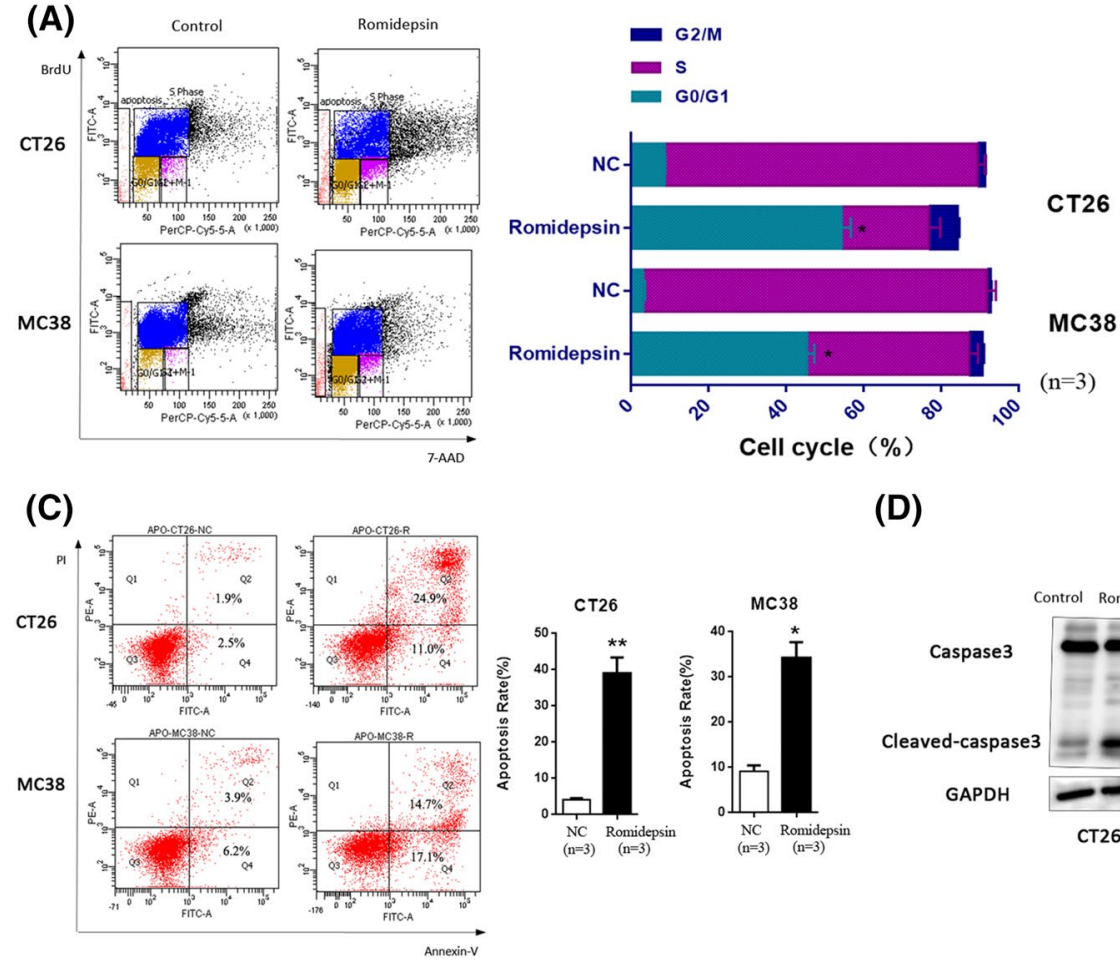

(D)
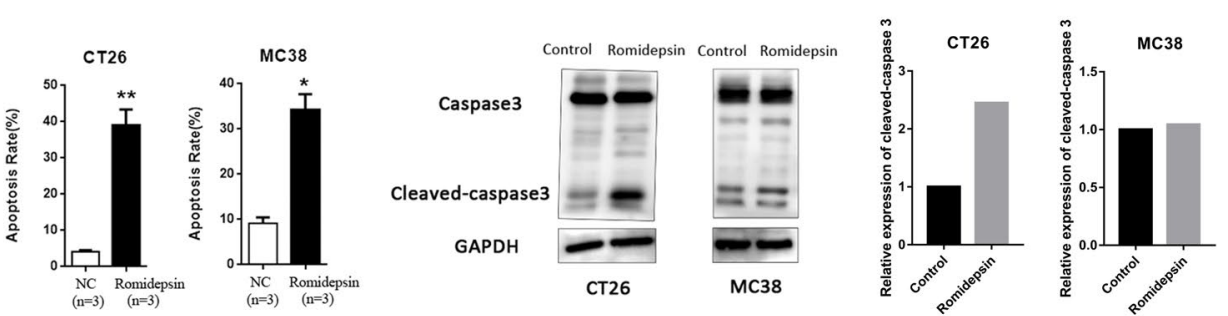

(B)

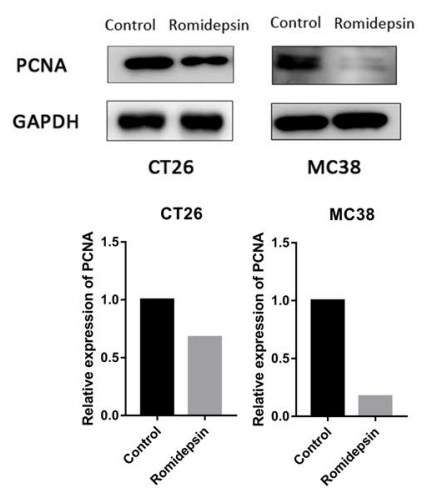

Fig. 1 Romidepsin inhibited proliferation, induced cell cycle arrest and increased apoptosis in CT26 and MC38 cells. a The effects of romidepsin on the cell cycle were evaluated in murine colon cancer cell lines. CT26 and MC38 cells were treated with or without romidepsin $(10 \mu \mathrm{M}$ for CT26 cells and $40 \mathrm{nM}$ for MC38 cells) for $24 \mathrm{~h}$ and then cultured with Brdu $(10 \mathrm{ul} / \mathrm{mL})$ for $4 \mathrm{~h}$. The cell cycle profile was measured by flow cytometry to detect the incorporation of Brdu into DNA during cell proliferation. The bar chart displays the percentages of cells in each phase. Three replicates $(n=3)$ were set for each experimental group. b Expression levels of PCNA were determined by western blot with anti-PCNA antibodies. The histogram was used to analyze the fold change of sample grayscale from western blot result. c Apoptosis was examined using an Annexin V/PI assay. The cells in the region of Q2 and Q4 were defined as apoptotic cells. Three replicates $(n=3)$ were set for each experimental group. d The level of caspase- 3 was determined by Western blot. The histogram was used to analyze the fold change of sample grayscale from western blot result $(* P<0.05, * * P<0.01)$ 
(A)
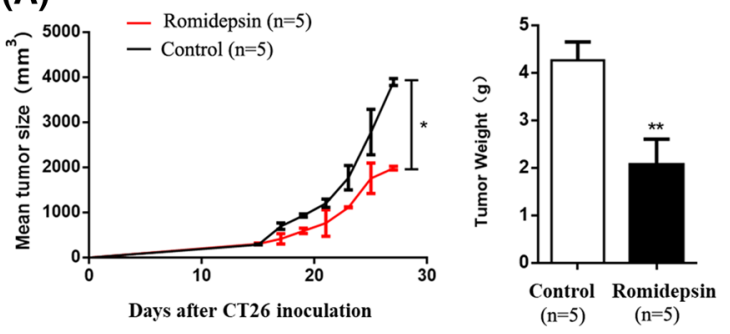

(C)

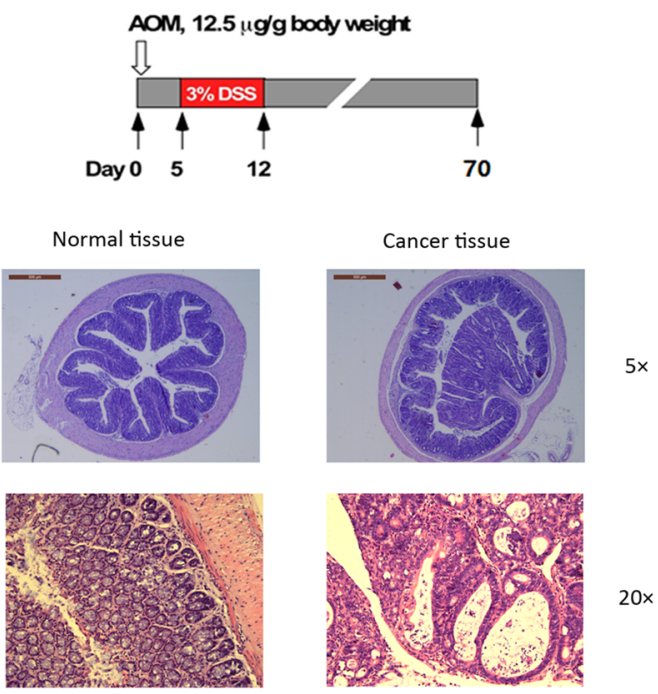

Fig. 2 Romidepsin inhibited the growth of murine colon cancer in vivo. a Subcutaneous transplantation tumor mouse models were established by inoculating CT26 cells. A total of 10 mice were divided into two groups. When the subcutaneous transplanted tumors were visible on day 15 , the experimental group $(n=5)$ was treated with romidepsin $(1 \mathrm{mg} / \mathrm{kg})$ every 2 days while the control group $(n=5)$ was injected with saline. Tumors were collected and weighed on day 30. The left line graph reflects the change of tumor size after treatment with or without romidepsin. The right histogram reflects the final difference of tumor weight between different groups. b Western blot was used to analyze the expression levels of PCNA and cas-

Following treatment with romidepsin, the qRT-PCR and Western blotting assay results showed that the cells experienced PD-L1 upregulation at both the mRNA and protein levels (Fig. 3a, b). These findings were further confirmed by evaluating the mean fluorescence intensity (MFI) of PD-L1 using flow cytometry (Fig. 3c). The ability of romidepsin to upregulate PD-L1 in vivo was also investigated using a subcutaneous transplantation tumor model and a CAC model. After treatment with romidepsin, PD-L1 expression in the tumors was assessed by qRTPCR and Western blotting. Consistent with the in vitro data, romidepsin treatment could significantly increase the PD-L1 expression in tumors (Fig. 3d, e).
(B)
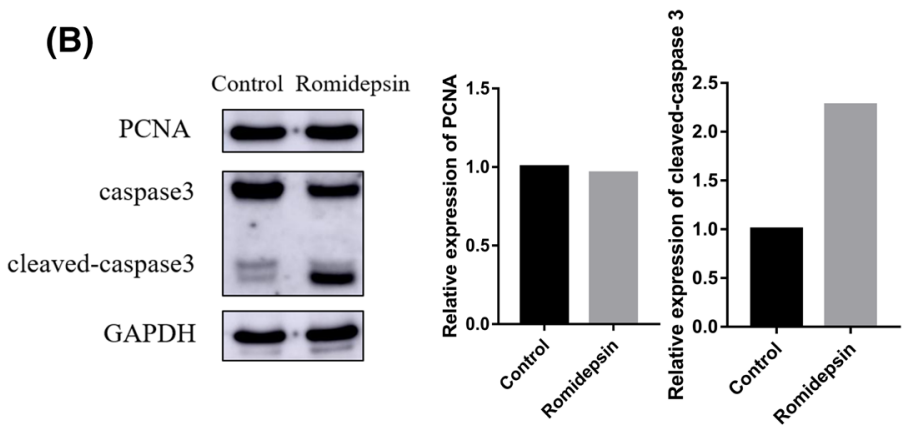

(D)
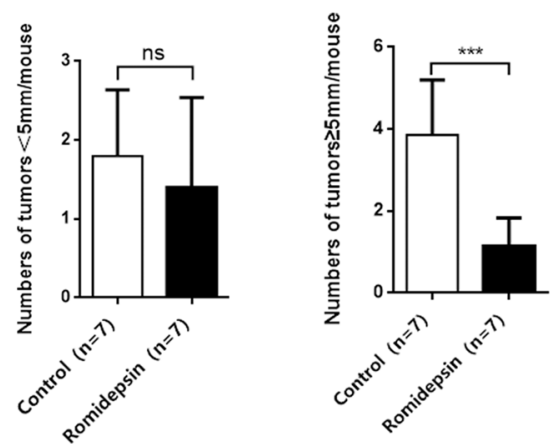

pase 3 in control and romidepsin group. $\mathbf{c}$ In colitis-associated cancer (CAC) models, mice were treated with AOM $(12.5 \mu \mathrm{g} / \mathrm{g}$ body weight $)$ by intraperitoneal injection on the first day and 3\% DSS in their drinking water from day 5 to day 12 . The mice were continuously fed until killing on the 70th day, and the colon tumor was paraffinembedded and stained with H\&E. d Fourteen mice with colitis-associated cancer were randomly divided into two groups, and each group was treated with or without romidepsin $(1 \mathrm{mg} / \mathrm{kg}$, on days 71,73 and 75). The average number of tumors per mouse was divided into two groups based on size $(<5 \mathrm{~mm}$ and $\geq 5 \mathrm{~mm}$ in the largest dimension) $(* P<0.05, * * P<0.01, * * * P<0.001)$

\section{Romidepsin increased PD-L1 expression by regulating histone acetylation and BRD4}

Because romidepsin enhanced PD-L1 expression in colon cancer cells, we examined the possible mechanisms by which romidepsin regulated PD-L1 expression. The histone acetylation state and expression levels of BRD4, a transcription factor for PD-L1, were analyzed before and after treatment with romidepsin. After treatment with romidepsin, the acetylation of histone 3 and histone 4 at different lysine sites was increased (Fig. 4a, b). In addition to the acetylation of histones 3 and 4 , we detected the role of bromodomain-containing proteins (BRD4) in PD-L1 expression upregulation by romidepsin. BRD4 
(A)

(B)

CT26

MC38

Oh $24 \mathrm{~h} 48 \mathrm{~h} 72 \mathrm{~h} 96 \mathrm{~h} 120 \mathrm{~h}$

Oh $24 \mathrm{~h} 48 \mathrm{~h} 72 \mathrm{~h} 96 \mathrm{~h} 120 \mathrm{~h}$

PD-L1

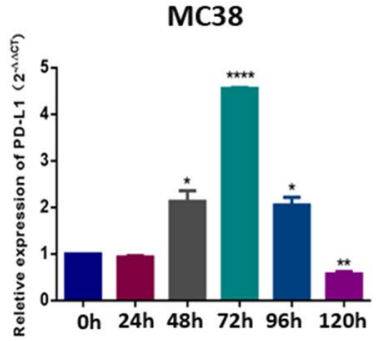

GAPDH

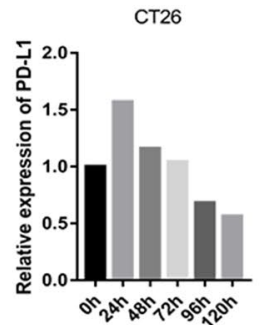

(C)
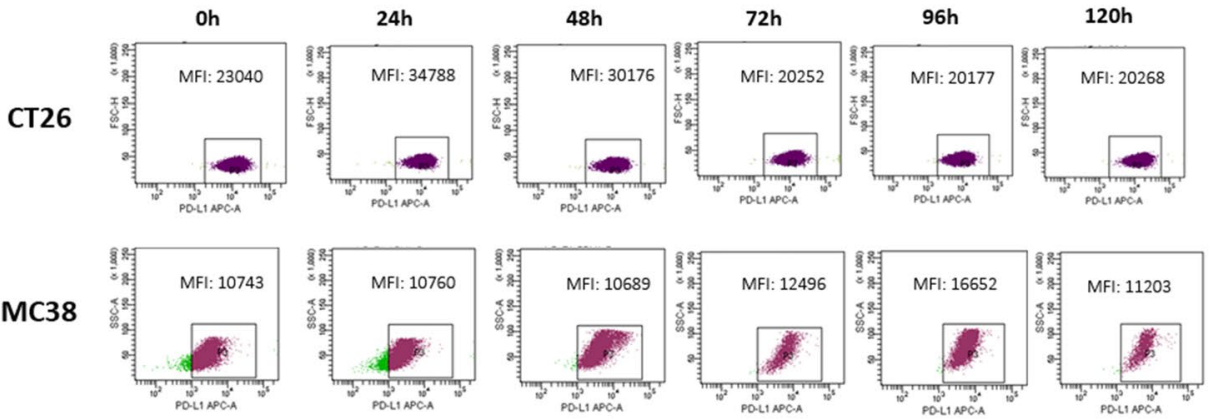
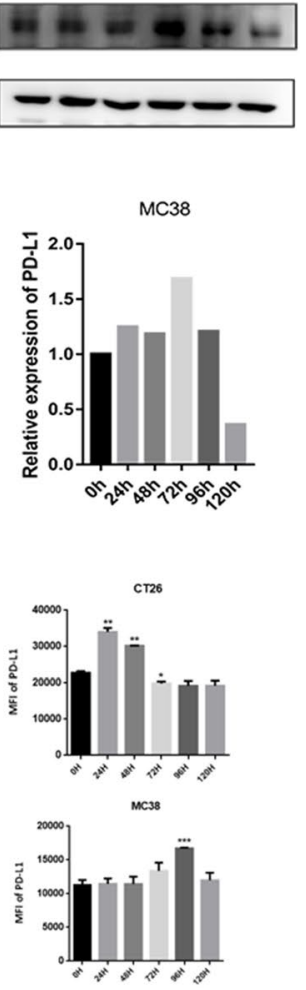

(D)
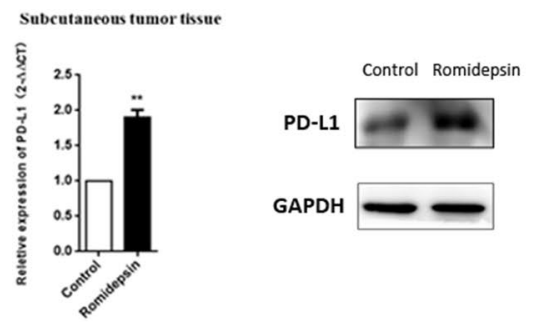

(E)
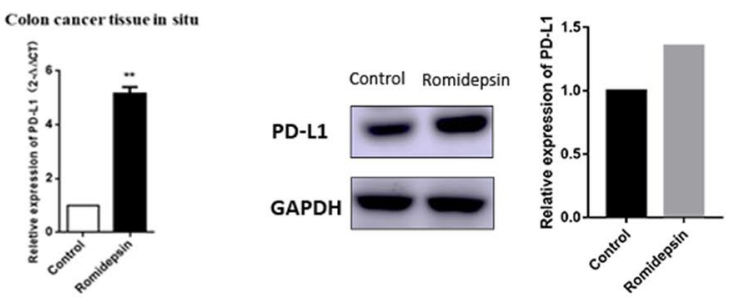

Fig. 3 Romidepsin upregulation of PD-L1 expression in murine colon cancer cells. a The mRNA level of PD-L1 in CT26 and MC38 cells was detected through qRT-PCR after treated with romidepsin for $0,24,48,72,96$ and $120 \mathrm{~h}$. Each experiment was repeated three times. b The protein level of PD-L1 in colon cancer cells was assayed by western blot. $\mathbf{c}$ The expression of PD-L1 on the surface of colon cancer cells was analyzed by mean fluorescence intensity (MFI) using flow cytometry. d In subcutaneous transplantation tumor models,

plays a critical role in regulating the transcription of PD-L1, whose binding sites are acetylated lysines 5 and 8 of histone H4 (H4K5ac/K8ac). Pools of three siRNAs (100 nM in total) were used to inhibit BRD4 expression in CT26 and MC38 cells (Fig. 4c). The effects of upregulating PD-L1 via romidepsin in the BRD4 knockdown group were much less than those in the control group (Fig. 4d), which indicated that BRD4 participated in regulating PD-L1 via romidepsin.

the mRNA levels of PD-L1 in control group $(n=5)$ and romidepsin group $(n=5)$ were determined by qRT-PCR, and $t$-test was used for statistics in the left. The protein levels of PD-L1 were determined by western blot in the middle and right. e In CAC models, the mRNA levels of PD-L1 in control group $(n=7)$ and romidepsin group $(n=7)$ were determined by qRT-PCR, and $t$ test was used for statistics in the left. The protein levels of PD-L1 were determined by western blot in the middle and right $(* P<0.05, * * P<0.01, * * * P<0.001)$

\section{Romidepsin increased the prevalence of Tregs, but combination with an anti-PD-1 antibody reversed this effect}

Because romidepsin increased the expression of PD-L1 in colon cancer cells, we next evaluated the influence of romidepsin on $\mathrm{T}$ cells, which was mediated by crosstalk between cancer cells and T cells through PD-L1/PD-1 signaling. Subcutaneous transplantation tumor models and 
(A)

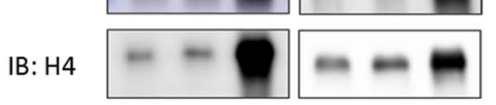

( R: Romidepsin )
(B)

CT26

MC38

Control Romidepsin

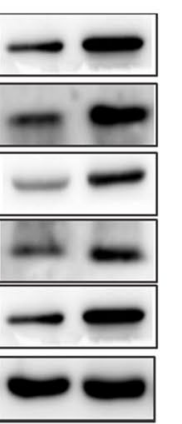

(C)

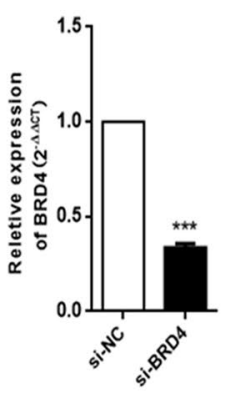

si-NC si-BRD4

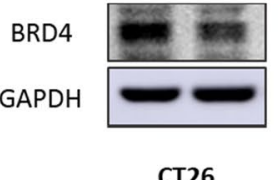

CT26

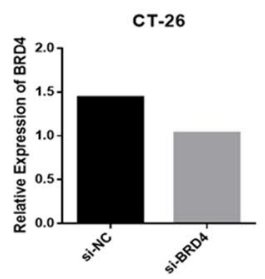

MC38

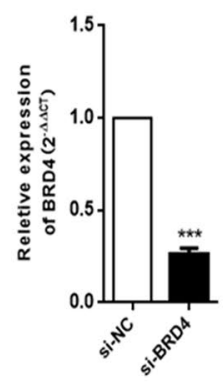

si-NC si-BRD4

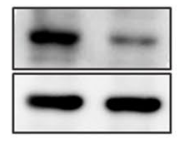

MC38

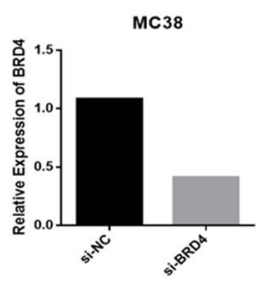

СТ26

(D)
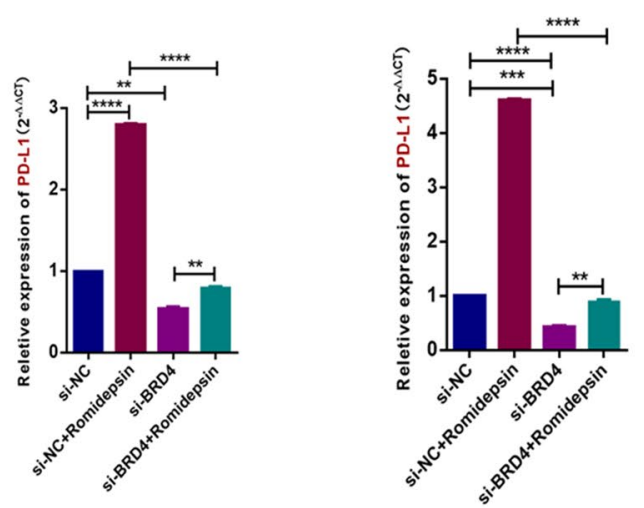

si-NC si-NC si-BRD4 si-BRD4 si-NC si-NC si-BRD4 si-BRD4

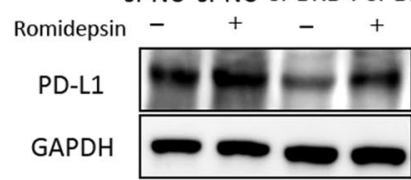

CT26

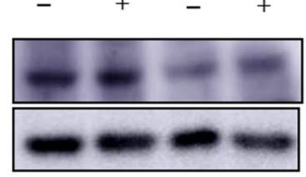

MC38

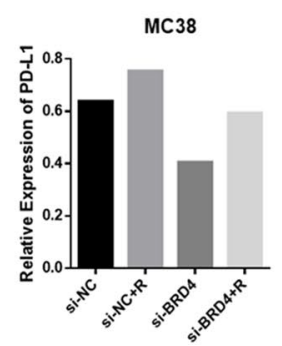

Fig. 4 Romidepsin induced PD-L1 expression by regulating histone acetylation and BRD4. a CT26 and MC38 cells were treated with romidepsin for $24 \mathrm{~h}$. Acetylated proteins in the cells were harvested by immunoprecipitation. Western blotting was used to measure the levels of histone $\mathrm{H} 3 / \mathrm{H} 4$ acetylated proteins. b The acetylation levels of histone H4-Lys5, H4-Lys8, H4-Lys16, H3-Lys9/14 and H3-Lys27 sites were analyzed by western blot after treatment with control or romidepsin. c A pool of three siRNAs (100 nM in total) was intro- duced into CT26 and MC38 cells to knock down BRD4. The BRD4 expression in these cells was measured via RT-qPCR and western blot. The western blot signals had been quantified and relative expression level was showed. d CT26 and MC38 cells were treated with si-NC, si-NC + romidepsin, si-BRD4 and si-BRD4+romidepsin, respectively. The PD-L1 expression in different groups was measured by qRT-PCR and western blot $(* P<0.05, * * P<0.01, * * * P<0.001)$ 
CAC models were used to assess the effect. These mice were treated with romidepsin (R), anti-PD-1 antibody (P), combination treatment $(\mathrm{R}+\mathrm{P})$ or saline (control). The percentages of Foxp3 + Tregs in the blood, spleen, tumors and bone marrow were quantified by flow cytometry assays (Fig. 5a). Mice in the romidepsin group had a significantly higher percentage of Foxp3+ Tregs than the control group, and this effect was partially reversed when combined with the anti-PD-1 treatment (Fig. 5b). This phenomenon could be observed in subcutaneously transplanted tumor mice and in only the blood and tumors of CAC mice (Fig. 5b). Furthermore, to determine the role of romidepsin in Foxp3+ Treg regulation, we sorted $\mathrm{CD} 4+\mathrm{CD} 25+\mathrm{T}$ cells from the spleens of BABL/c mice by MACS. The expression of Foxp3 in CD4+ CD25+ T cells was significantly increased after treatment with romidepsin (Fig. 5c).

\section{Romidepsin decreased the Th1/Th2 ratio and IFN- $\gamma$ secretion of CD8+ T cells, while combination with an anti-PD-1 antibody reversed these effects}

Intracellular T-helper 1/T-helper 2 (Th1/Th2) cytokines, including IFN- $\gamma$ and IL-4, were detected by flow cytometric assays. In blood and tumors of subcutaneously transplanted tumor mice and CAC mice, the Th1/Th2 ratio (shown by IFN- $\gamma /$ IL-4) was decreased after romidepsin treatment, which could be reversed when combined with anti-PD-1 treatment (Fig. 6a). IFN- $\gamma$ secretion was examined to evaluate the activation of CD8+ T cells. Flow cytometry showed that romidepsin decreased the prevalence of CD8+ IFN$\gamma+\mathrm{T}$ cells. When combined with the anti-PD-1 antibody, the percentage of CD8+ IFN- $\gamma+$ cells were increased than romidepsin treatment alone (Fig. 6b).

\section{Anti-tumor effects of romidepsin in combination with an anti-PD-1 antibody in vivo}

The anti-tumor effects of romidepsin and anti-PD-1 antibody co-treatment were evaluated in subcutaneously transplanted tumor mice and in CAC mice. In subcutaneously transplanted tumor mice, the inhibitory effect of the co-treatment on the tumor growth was significantly increased compared with the treatment with romidepsin alone. And compared with anti-PD-1 antibody treatment, the tumor suppression effect of the combination therapy also showed an increasing trend (Fig. 7a). The incidences and multiplicity of colon neoplasms in CAC mice are shown in Fig. 7b. The average number of tumors $\geq 5 \mathrm{~mm}$ per mouse in the romidepsin combined with anti-PD-1 blockade treatment group tended to be less than that in the romidepsin treatment only group. In addition, compared with anti-PD-1 treatment, the group of combination also had an advantage in efficacy with no significant statistically difference.

\section{Discussion}

Romidepsin is an HDACi involved in regulating cell proliferation, differentiation and apoptosis by promoting chromatin uncoiling, histone acetylation and genes transcription. Previous work with romidepsin indicated that it had considerable anti-tumor effects in solid tumors [18-20].

In our study, after being treated with romidepsin, the proportion of colon cancer cells in the G0/G1 phase increased significantly, while cells in the $S+G 2 / M$ phase decreased. Romidepsin can induce cell cycle arrest and inhibit cell proliferation. In addition, romidepsin also promotes cell apoptosis, which was verified by changes of cleaved-caspase 3. Furthermore, romidepsin can inhibit tumor growth in vivo in both subcutaneous tumor-transplanted models and CAC models.

Beyond the direct suppression of tumor cells, romidepsin has been reported to have the ability to regulate the immune system $[14,21]$. We found that PD-L1 was upregulated in colon cancer cells and tissues after being treated with romidepsin, which can be explained by two mechanisms. First, romidepsin increased the level of acetylation of histone $\mathrm{H} 3 / \mathrm{H} 4$ in humor cells, which showed a positive correlation with the expression of PD-L1. The result is consistent with previous understanding of the regulation of PD-L1 expression, that is, HDACis enhance the expression of PD-L1 by increasing the acetylation of histone $\mathrm{H} 3 / \mathrm{H} 4$ at the promoter region of PD-L1 genes [14]. In addition, we also found that the expression of PD-L1 was related to the transcription factor BRD4 after being treated with romidepsin. BRD4, a novel class of epigenetic "readers", are involved in the long-term control of genome activity through their ability to bind with acetylated lysine residues in histones [22]. It has been reported that acetylated lysine 5 and 8 of nucleosome histone $\mathrm{H} 4$ (H4K5ac/K8ac), which were upregulated after romidepsin treatment, are BRD4 binding sites [23]. When BRD4 in CT26 and MC38 cells was knocked down, the effect of romidepsin on up-regulating PD-L1 expression was greatly reduced. Therefore, it is reasonable to speculate that romidepsin can upregulate the expression of PD-L1 by regulating BRD4 [24-26].

Although the mechanism of PD-L1 upregulation after romidepsin treatment were elucidated as above, the effect of this change on anti-tumor immune response has been controversial. PD-L1 is an important immunomodulatory molecule. Mechanistically, after the combination of PD-1 receptor on T cells and its ligand PD-L1, tyrosine phosphatases are recruited to dephosphorylate downstream effector molecules and thereby attenuate $\mathrm{T}$ cell receptor (TCR)-mediated signaling, which ultimately inhibits T cell proliferation and cytokine production $[27,28]$. PD-1 blocking antibodies have the ability to inhibit the PD-L1/ 
(A)

Subcutaneous transplantation tumor
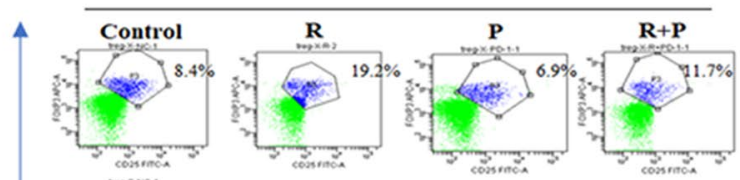

Foxp3
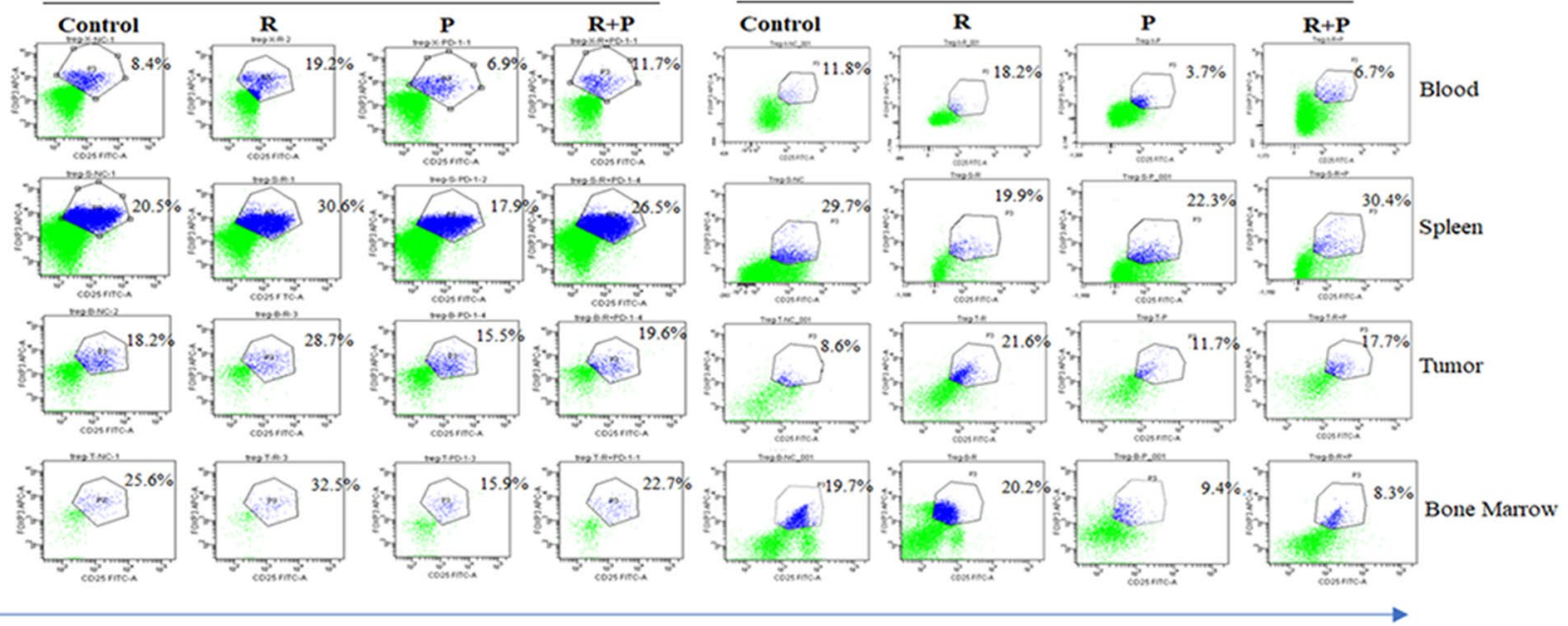

$\mathrm{CD} 25$
Subcutaneous transplantation tumor

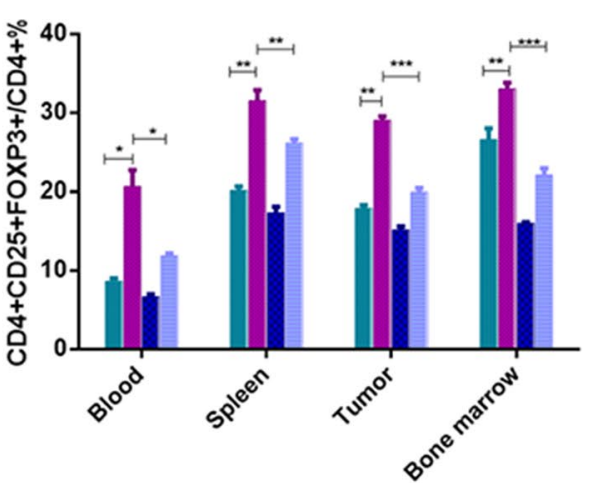

Control

- Romidepsin

anti-PD-1 antibody

= Romidepsin+anti-PD-1 antibody

(C)
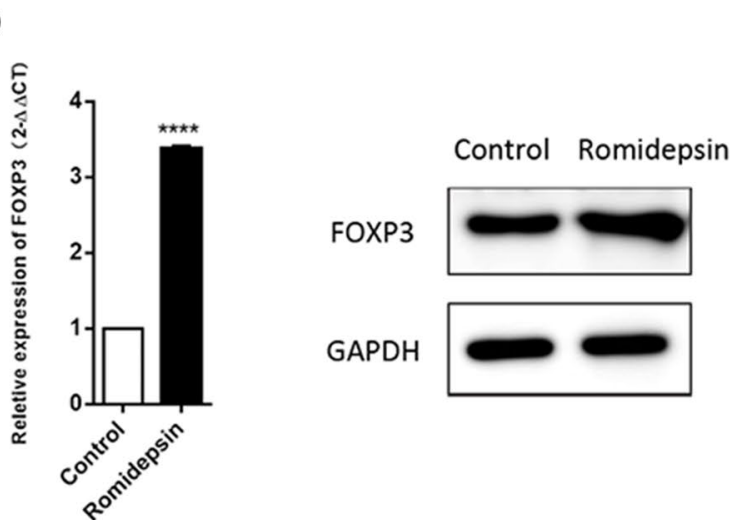

Colon cancer in situ
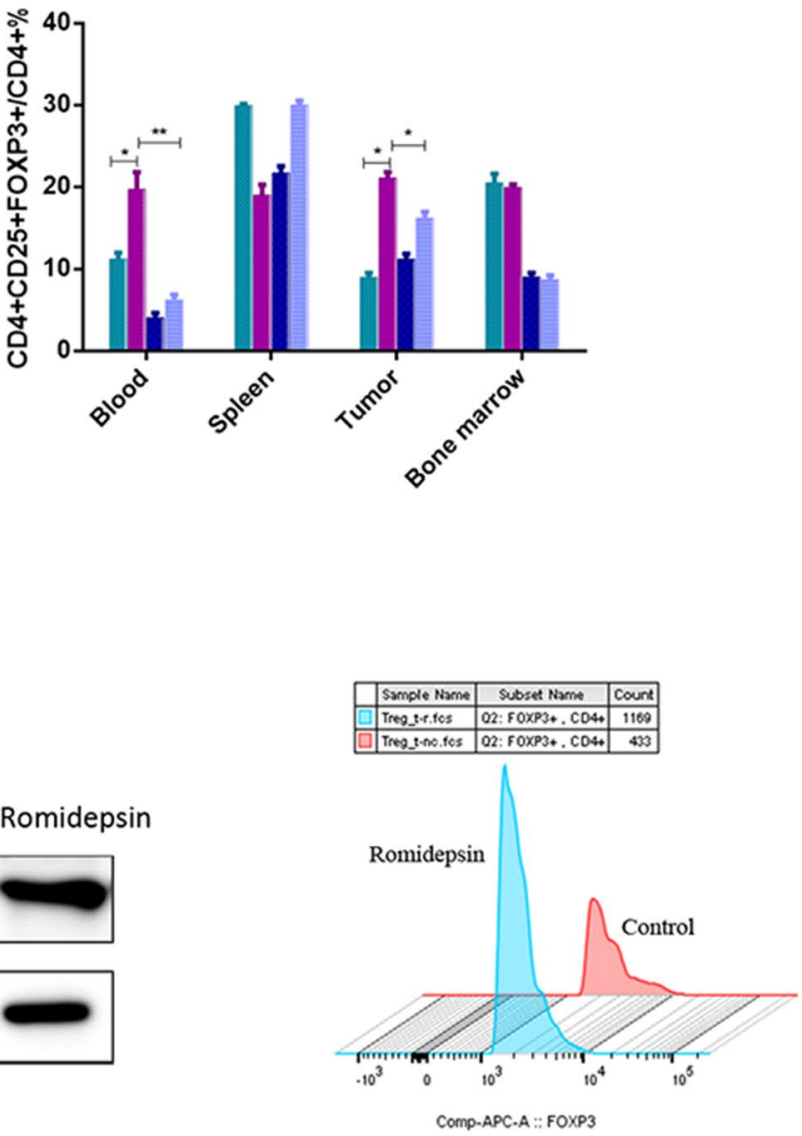

Fig. 5 Romidepsin increased the prevalence of FOXP3+Tregs in vivo. a Subcutaneous transplantation tumor mice and CAC mice were treated with romidepsin (R), anti-PD-1 antibody $(\mathrm{P})$, combination treatment $(\mathrm{R}+\mathrm{P})$ or saline (control). Flow cytometry was conducted to detect Foxp3 + Tregs in the blood, spleen, tumor and bone marrow. b The percentage of $\mathrm{CD} 4+\mathrm{CD} 25+$ Foxp $3+$ Tregs in $\mathrm{CD} 4+\mathrm{T}$ cells after four treatments (control, romidepsin, antiPD-1 antibody, romidepsin + anti-PD-1 antibody) was described. c $\mathrm{CD} 4+\mathrm{CD} 25+\mathrm{T}$ cells were sorted from the spleens of BABL/c mice by MACS and treated with romidepsin for $24 \mathrm{~h}$. The expression level of Foxp3 in CD4 + CD25 + T cells was analyzed by qRT-PCR, western blot and flow cytometry $(* P<0.05, * * P<0.01$, $* * * P<0.001)$ 
(A)
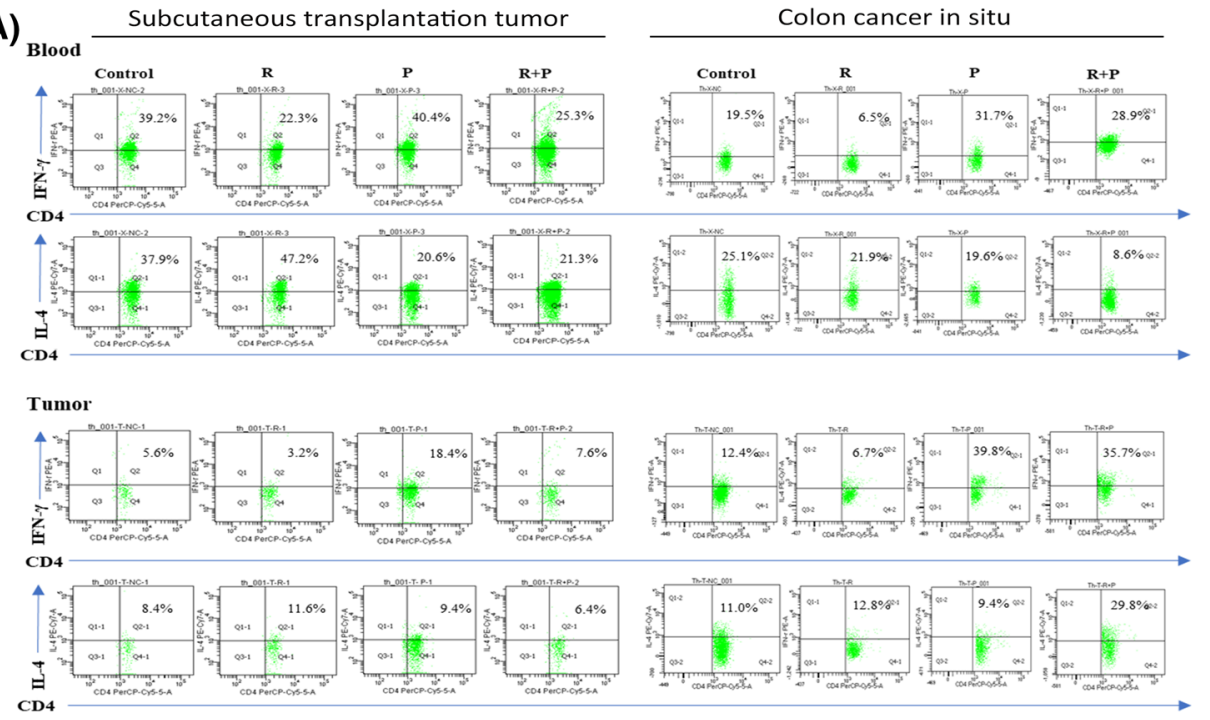

Subcutaneous transplantation tumor

Colon cancer in situ
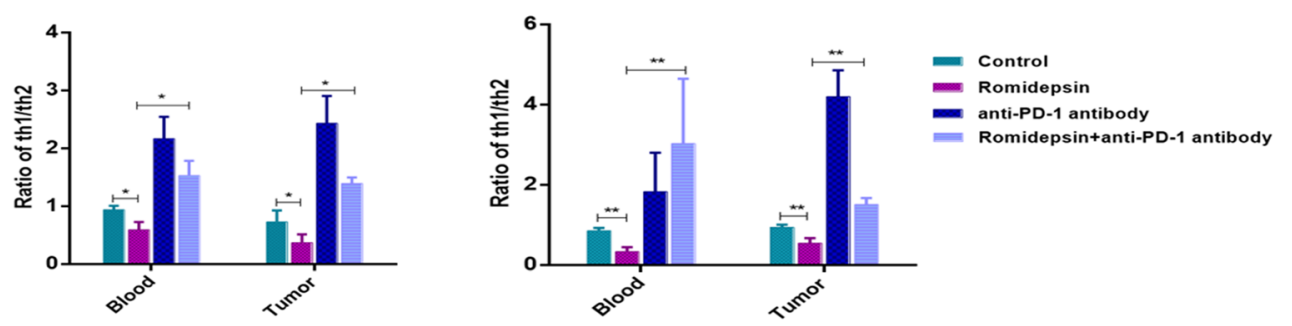

(B)

Subcutaneous transplantation tumor

Colon cancer in situ
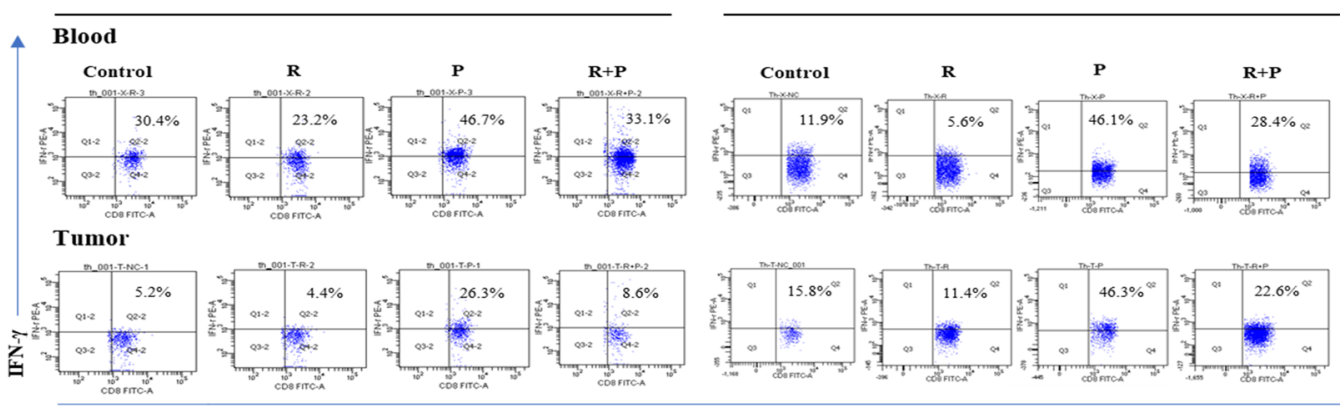

Subcutaneous transplantation tumor

Colon cancer in situ
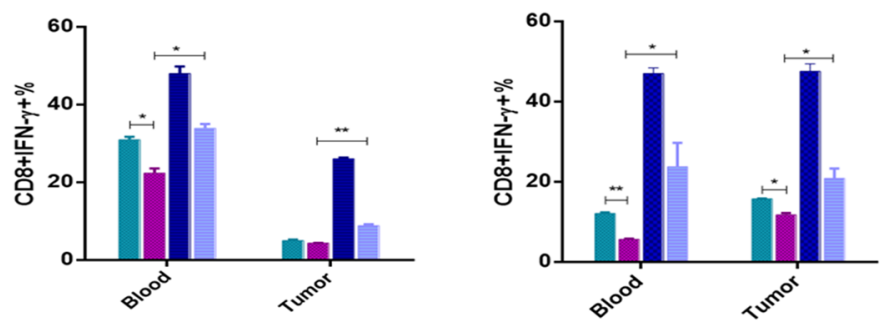

- Control

- Romidepsin

- anti-PD-1 antibody

- Romidepsin+anti-PD-1 antibody

Fig. 6 Romidepsin decreased the Th1/Th2 ratio and IFN- $\gamma$ secretion by $\mathrm{CD} 8+\mathrm{T}$ cells. a In blood and tumors of the subcutaneous transplantation tumor model and CAC model (5 mice in each group), the levels of IFN- $\gamma$ and IL-4 in CD $4+\mathrm{T}$ cells were detected by flow cytometry after treatment. The ratio of IFN- $\gamma / \mathrm{IL}-4$ was

analyzed, which could reveal the Th1/Th2 balance. b The state of IFN- $\gamma+\mathrm{CD} 8+\mathrm{T}$ cells under different treatments was assayed by flow cytometry in the subcutaneous transplantation tumor model and CAC model $(P<0.05, * * P<0.01, * * * P<0.001$, $* * * * P<0.0001)$ 


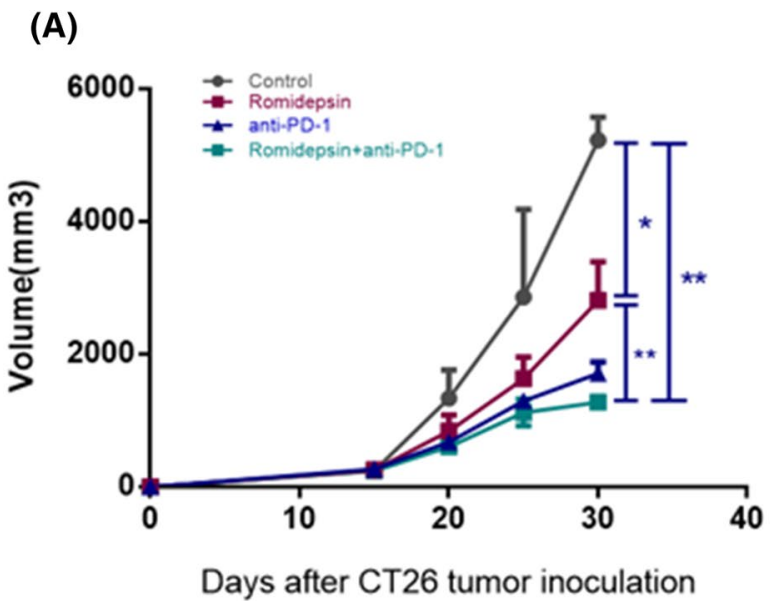

(B)

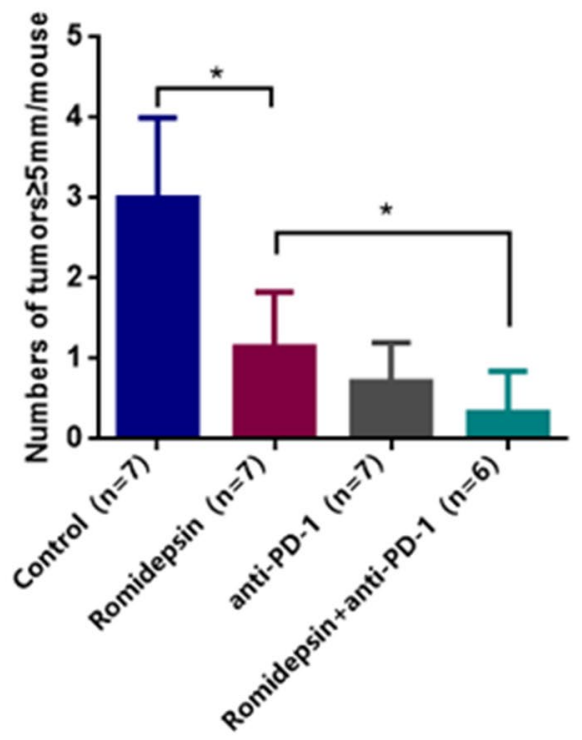

Fig. 7 Anti-tumor effects of romidepsin in combination with an antiPD-1 antibody. a The size and weight of tumors were analyzed as therapeutic indicators under the treatment of romidepsin, anti-PD-1 antibody and combination of two drugs. b Twenty-eight mice with colitis-associated cancer were randomly divided into four groups,

PD-1 pathway and restore $\mathrm{T}$ cell function. On the one hand, the expression of PD-L1 on tumor cells negatively regulates $\mathrm{T}$ cell responses and allows immune escape $[29,30]$. On the other hand, increasing evidences show that HDACi-induced upregulation of PD-L1 can increase $\mathrm{T}$ cell infiltration, upregulate antigen presentation and thus enhance the efficacy of anti-PD-1 immunotherapy $[21,31,32]$. Our results indicate that the upregulation of PD-L1 expression induced by romidepsin treatment suppresses cellular immune functions in colon cancer, including downregulating the ratio of Th1/Th2 cells (shown as IFN- $\gamma / \mathrm{IL}-4)$ and the secretion of IFN- $\gamma$ in CD8+ T cells,

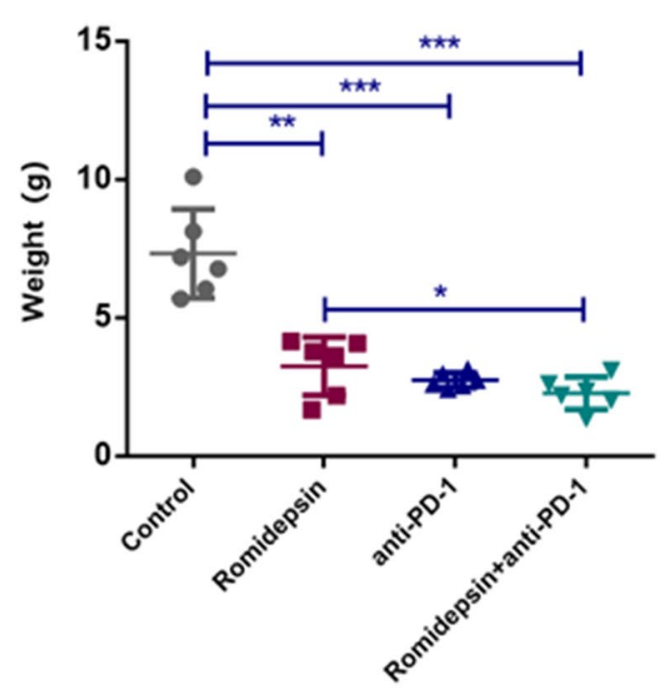

which were treated with saline, romidepsin, anti-PD-1 antibody and romidepsin + anti-PD-1 antibody, respectively. After the treatment, the average number of tumors per mouse $(\geq 5 \mathrm{~mm}$ in the largest dimension) was analyzed to evaluate efficacy $(P<0.05, * * P<0.01$, $* * * P<0.001, * * * * P<0.0001)$

as well as upregulating the percentage of Foxp3+ Tregs. The effect of HDAC inhibitors on Tregs differentiation has been previously reported. HDAC inhibitors can promote the expression of Foxp3 and preserve Foxp3 lysine $\varepsilon$-acetylation, which will inhibit the ubiquitination degradation of Foxp3 and enhance its binding to DNA [16]. Foxp3 binds to DNA and regulates the transcription of multiple genes in Treg cells, thereby promoting Treg development and immunosuppressive function [15-17, 33]. In our research, romidepsin is likely to increase the percentage of Tregs by upregulating Foxp3 expression. 
Even if romidepsin treatment produced a series of immunosuppression, the results of subcutaneous tumor-transplanted models and CAC models confirmed its inhibitory effect on tumor growth. And due to its immune relevance, the combined strategy of HDACis and anti-PD-1 immunotherapy was inspired. Compared with the treatment of romidepsin or anti-PD-1 antibodies alone, the combination of the two drugs not only downregulates the immunosuppression of romidepsin but also increases the tumor killing effect of anti-PD-1 immunotherapy, ultimately achieving the optimal anti-tumor effect. Therefore, the combination of romidepsin and anti-PD-1 antibody provides a more potential option for colon cancer treatment.

Author contributions Investigation, YS; methodology, YF, XZ, GZ, YY, GM, SB; resources, YG; conceptualization, HL.

Funding This research was funded by the National Natural Science Foundation of China (81772620), the National Key R\&D Program of China (2018ZX09201015) and Tianjin Science and Technology Major Project of Chronic Diseases Prevention and Control (17ZXMFSY00130).

\section{Compliance with ethical standards}

Conflict of interest The authors declare no conflict of interest.

Ethical approval All procedures performed in studies involving animals were in accordance with the ethical standards of The Animal Ethical and Welfare Committee of Tianjin Medical University Cancer Institute and Hospital (AE2014035).

Cell line authentication The mouse colon cancer cell lines CT26 and MC38 were obtained from the ATCC (Manassas, VA, USA). Because these cell lines are purchased from professional vendors, the authentication is not required.

Open Access This article is licensed under a Creative Commons Attribution 4.0 International License, which permits use, sharing, adaptation, distribution and reproduction in any medium or format, as long as you give appropriate credit to the original author(s) and the source, provide a link to the Creative Commons licence, and indicate if changes were made. The images or other third party material in this article are included in the article's Creative Commons licence, unless indicated otherwise in a credit line to the material. If material is not included in the article's Creative Commons licence and your intended use is not permitted by statutory regulation or exceeds the permitted use, you will need to obtain permission directly from the copyright holder. To view a copy of this licence, visit http://creativecommons.org/licenses/by/4.0/.

\section{References}

1. Barneda-Zahonero B, Parra M (2012) Histone deacetylases and cancer. Mol Oncol 6(6):579-589. https://doi.org/10.1016/j.molon c. 2012.07 .003

2. Halaburkova A, Jendzelovsky R, Koval J, Herceg Z, Fedorocko P, Ghantous A (2017) Histone deacetylase inhibitors potentiate photodynamic therapy in colon cancer cells marked by chromatinmediated epigenetic regulation of CDKN1A. Clin Epigenet. https ://doi.org/10.1186/s13148-017-0359-x

3. Briere D, Sudhakar N, Woods DM, Hallin J, Engstrom LD, Aranda R, Chiang H, Sodre AL, Olson P, Weber JS, Christensen JG (2018) The class I/IV HDAC inhibitor mocetinostat increases tumor antigen presentation, decreases immune suppressive cell types and augments checkpoint inhibitor therapy. Cancer Immunol Immunother 67(3):381-392. https://doi.org/10.1007/s0026 2-017-2091-y

4. Knox T, Sahakian E, Banik D, Hadley M, Palmer E, Noonepalle S, Kim J, Powers J, Gracia-Hernandez M, Oliveira V, Cheng F, Chen J, Barinka C, Pinilla-Ibarz J, Lee NH, Kozikowski A, Villagra A (2019) Selective HDAC6 inhibitors improve anti-PD-1 immune checkpoint blockade therapy by decreasing the anti-inflammatory phenotype of macrophages and down-regulation of immunosuppressive proteins in tumor cells. Sci Rep 9(1):6136. https://doi. org/10.1038/s41598-019-42237-3

5. Fournel M, Bonfils C, Hou Y, Yan PT, Trachy-Bourget MC, Kalita A, Liu J, Lu AH, Zhou NZ, Robert MF, Gillespie J, Wang JJ, SteCroix H, Rahil J, Lefebvre S, Moradei O, Delorme D, Macleod AR, Besterman JM, Li Z (2008) MGCD0103, a novel isotypeselective histone deacetylase inhibitor, has broad spectrum antitumor activity in vitro and in vivo. Mol Cancer Ther 7(4):759-768. https://doi.org/10.1158/1535-7163.Mct-07-2026

6. Xu WS, Parmigiani RB, Marks PA (2007) Histone deacetylase inhibitors: molecular mechanisms of action. Oncogene 26(37):5541-5552. https://doi.org/10.1038/sj.onc. 1210620

7. Richon VM, Sandhoff TW, Rifkind RA, Marks PA (2000) Histone deacetylase inhibitor selectively induces p21WAF1 expression and gene-associated histone acetylation. Proc Natl Acad Sci USA 97(18):10014-10019. https://doi.org/10.1073/pnas.18031 6197

8. Shao Y, Gao Z, Marks PA, Jiang X (2004) Apoptotic and autophagic cell death induced by histone deacetylase inhibitors. Proc Natl Acad Sci USA 101(52):18030-18035. https://doi. org/10.1073/pnas.0408345102

9. Wilson AJ, Lalani AS, Wass E, Saskowski J, Khabele D (2012) Romidepsin (FK228) combined with cisplatin stimulates DNA damage-induced cell death in ovarian cancer. Gynecol Oncol 127(3):579-586. https://doi.org/10.1016/j.ygyno.2012.09.016

10. Sun WJ, Huang H, He B, Hu DH, Li PH, Yu YJ, Zhou XH, Lv Z, Zhou L, Hu TY, Yao ZC, Lu MD, Shen X, Zheng ZQ (2017) Romidepsin induces G2/M phase arrest via Erk/cdc25C/cdc2/ cyclinB pathway and apoptosis induction through JNK/c-Jun/ caspase3 pathway in hepatocellular carcinoma cells. Biochem Pharmacol 127:90-100. https://doi.org/10.1016/j.bcp.2016.12.008

11. Ciardiello C, Roca MS, Noto A, Bruzzese F, Moccia T, Vitagliano C, Di Gennaro E, Ciliberto G, Roscilli G, Aurisicchio L, Marra E, Mancini R, Budillon A, Leone A (2016) Synergistic antitumor activity of histone deacetylase inhibitors and antiErbB3 antibody in NSCLC primary cultures via modulation of ErbB receptors expression. Oncotarget 7(15):19559-19574. https ://doi.org/10.18632/oncotarget.7195

12. Roulois D, Blanquart C, Panterne C, Gueugnon F, Grégoire M, Fonteneau JF (2012) Downregulation of MUC1 expression and its recognition by $\mathrm{CD} 8^{+} \mathrm{T}$ cells on the surface of malignant pleural mesothelioma cells treated with HDACi. Eur J Immunol 42(3):783-789. https://doi.org/10.1002/eji.201141800

13. Andresen L, Jensen H, Pedersen MT, Hansen KA, Skov S (2007) Molecular regulation of MHC class I chain-related protein A expression after HDAC-inhibitor treatment of Jurkat T cells (Baltimore, Md : 1950). J Immunol 179(12):8235-8242. https://doi. org/10.4049/jimmunol.179.12.8235

14. Woods DM, Sodré AL, Villagra A, Sarnaik A, Sotomayor EM, Weber J (2015) HDAC inhibition upregulates PD-1 ligands in 
melanoma and augments immunotherapy with PD-1 blockade. Cancer Immunol Res 3(12):1375-1385. https://doi. org/10.1158/2326-6066.Cir-15-0077-t

15. Wang L, Beier UH, Akimova T, Dahiya S, Han R, Samanta A, Levine MH, Hancock WW (2018) Histone/protein deacetylase inhibitor therapy for enhancement of Foxp3+ T-regulatory cell function posttransplantation. Am J Transpl 18(7):1596-1603. https://doi.org/10.1111/ajt.14749

16. Beier UH, Akimova T, Liu Y, Wang L, Hancock WW (2011) Histone/protein deacetylases control Foxp3 expression and the heat shock response of T-regulatory cells. Curr Opin Immunol 23(5):670-678. https://doi.org/10.1016/j.coi.2011.07.002

17. Sugimoto K, Itoh T, Takita M, Shimoda M, Chujo D, SoRelle JA, Naziruddin B, Levy MF, Shimada M, Matsumoto S (2014) Improving allogeneic islet transplantation by suppressing Th17 and enhancing Treg with histone deacetylase inhibitors. Transpl Int 27(4):408-415. https://doi.org/10.1111/tri.12265

18. Mizutani H, Hiraku Y, Tada-Oikawa S, Murata M, Ikemura K, Iwamoto T, Kagawa Y, Okuda M, Kawanishi S (2010) Romidepsin (FK228), a potent histone deacetylase inhibitor, induces apoptosis through the generation of hydrogen peroxide. Cancer Sci 101(10):2214-2219. https://doi.org/10.111 1/j.1349-7006.2010.01645.x

19. Panicker J, Li Z, McMahon C, Sizer C, Steadman K, PiekarZ R, Bates SE, Thiele CJ (2010) Romidepsin (FK228/depsipeptide) controls growth and induces apoptosis in neuroblastoma tumor cells. Cell Cycle 9(9):1830-1838. https://doi.org/10.4161/ cc.9.9.11543

20. Hegarty SV, Togher KL, O'Leary E, Solger F, Sullivan AM, O'Keeffe GW (2017) Romidepsin induces caspase-dependent cell death in human neuroblastoma cells. Neurosci Lett 653:12-18. https://doi.org/10.1016/j.neulet.2017.05.025

21. Zheng H, Zhao W, Yan C, Watson CC, Massengill M, Xie M, Massengill C, Noyes DR, Martinez GV, Afzal R, Chen Z, Ren X, Antonia SJ, Haura EB, Ruffell B, Beg AA (2016) HDAC inhibitors enhance T-Cell chemokine expression and augment response to PD-1 immunotherapy in lung adenocarcinoma. Clin Cancer Res 22(16):4119-4132. https://doi.org/10.1158/1078-0432. Ccr-15-2584

22. Hajmirza A, Emadali A, Gauthier A, Casasnovas O, Gressin R, Callanan MB (2018) BET family protein BRD4: an emerging actor in NFKB signaling in inflammation and cancer. Biomedicines. https://doi.org/10.3390/biomedicines6010016

23. Hu X, Lu X, Liu R, Ai N, Cao Z, Li Y, Liu J, Yu B, Liu K, Wang H, Zhou C, Wang Y, Han A, Ding F, Chen R (2014) Histone cross-talk connects protein phosphatase $1 \alpha(\mathrm{PP} 1 \alpha)$ and histone deacetylase (HDAC) pathways to regulate the functional transition of bromodomain-containing 4 (BRD4) for inducible gene expression. J Biol Chem 289(33):23154-23167. https://doi.org/10.1074/ jbc.M114.570812

24. Sun L, Xu R, Sun X, Duan Y, Han Y, Zhao Y, Qian H, Zhu W, Xu W (2016) Safety evaluation of exosomes derived from human umbilical cord mesenchymal stromal cell. Cytotherapy 18(3):413422. https://doi.org/10.1016/j.jcyt.2015.11.018

25. Hogg SJ, Vervoort SJ, Deswal S, Ott CJ, Li J, Cluse LA, Beavis PA, Darcy PK, Martin BP, Spencer A, Traunbauer AK, Sadovnik
I, Bauer K, Valent P, Bradner JE, Zuber J, Shortt J, Johnstone RW (2017) BET-bromodomain inhibitors engage the host immune system and regulate expression of the immune checkpoint ligand PD-L1. Cell Rep 18(9):2162-2174. https://doi.org/10.1016/j.celre p.2017.02.011

26. Riganti C, Lingua MF, Salaroglio IC, Falcomata C, Righi L, Morena D, Picca F, Oddo D, Kopecka J, Pradotto M, Libener R, Orecchia S, Bironzo P, Comunanza V, Bussolino F, Novello S, Scagliotti GV, Di Nicolantonio F, Taulli R (2018) Bromodomain inhibition exerts its therapeutic potential in malignant pleural mesothelioma by promoting immunogenic cell death and changing the tumor immune-environment. Oncoimmunology 7(3):e1398874. https://doi.org/10.1080/2162402X.2017.1398874

27. Patsoukis N, Brown J, Petkova V, Liu F, Li L, Boussiotis VA (2012) Selective effects of PD-1 on Akt and Ras pathways regulate molecular components of the cell cycle and inhibit $\mathrm{T}$ cell proliferation. Sci Signal 5(230):ra46. https://doi.org/10.1126/scisi gnal.2002796

28. Patsoukis N, Bardhan K, Chatterjee P, Sari D, Liu B, Bell LN, Karoly ED, Freeman GJ, Petkova V, Seth P, Li L, Boussiotis VA (2015) PD-1 alters T-cell metabolic reprogramming by inhibiting glycolysis and promoting lipolysis and fatty acid oxidation. Nat Commun 6:6692. https://doi.org/10.1038/ncomms7692

29. Hashimoto M, Kamphorst AO, Im SJ, Kissick HT, Pillai RN, Ramalingam SS, Araki K, Ahmed R (2018) CD8 T cell exhaustion in chronic infection and cancer: opportunities for interventions. Annu Rev Med 69:301-318. https://doi.org/10.1146/annur ev-med-012017-043208

30. West EE, Jin HT, Rasheed AU, Penaloza-Macmaster P, Ha SJ, Tan WG, Youngblood B, Freeman GJ, Smith KA, Ahmed R (2013) PD-L1 blockade synergizes with IL-2 therapy in reinvigorating exhausted T cells. J Clin Invest 123(6):2604-2615. https://doi. org/10.1172/JCI67008

31. Terranova-Barberio M, Thomas S, Ali N, Pawlowska N, Park J, Krings G, Rosenblum MD, Budillon A, Munster PN (2017) HDAC inhibition potentiates immunotherapy in triple negative breast cancer. Oncotarget 8(69):114156-114172. https://doi. org/10.18632/oncotarget.23169

32. Taube JM, Klein A, Brahmer JR, Xu H, Pan X, Kim JH, Chen L, Pardoll DM, Topalian SL, Anders RA (2014) Association of PD-1, PD-1 ligands, and other features of the tumor immune microenvironment with response to anti-PD-1 therapy. Clin Cancer Res 20(19):5064-5074. https://doi.org/10.1158/1078-0432. Ccr-13-3271

33. Wang L, de Zoeten EF, Greene MI, Hancock WW (2009) Immunomodulatory effects of deacetylase inhibitors: therapeutic targeting of FOXP3+ regulatory T cells. Nat Rev Drug Discov 8(12):969-981. https://doi.org/10.1038/nrd3031

Publisher's Note Springer Nature remains neutral with regard to jurisdictional claims in published maps and institutional affiliations. 